\title{
An Update and Review on Microwave Assisted Chemical Activation of Oil Sand Petroleum Coke
}

\author{
Shan Bai, Charles Q Jia and Donald W Kirk* \\ Department of Chemical Engineering and Applied Chemistry, University of Toronto, Canada
}

Submission: April 28, 2018; Published: May 03, 2018

*Corresponding author: Donald W Kirk, Department of Chemical Engineering and Applied Chemistry, University of Toronto, Toronto, Canada, Tel : +1 416-978-7406; Fax: +1 416-978-8605; Email: don.kirk@utoronto.ca

\begin{abstract}
This work provides an overview of the current status of microwave assisted chemical activation of oil sand petroleum coke. In recent years, microwave assisted chemical activation has drawn interests due to its high energy efficiency. This technique is widely applied in the research of biomass activation, but few studies have been done for oil sand petroleum coke activation. The abundance of oil sand petroleum coke and applications of its activated product create great potential for microwave activation. Although current work has proven the feasibility microwave assisted chemical activation of oil sand petroleum coke, optimization of activation conditions needs to be further studied for the wide application of this technique.
\end{abstract}

Keywords: Microwave; Chemical activation; Activated carbon; Oil sand petroleum coke

Abbreviations: OSPC: Oil Sand Petroleum Coke

\section{Introduction}

As of 2016, with proven oil sand reserves in Alberta totaled at 165.4 billion barrels (bbl), Canada is home to one of the world's largest reserves [1]. As a by-product from oil sand extraction and bitumen upgrading, Alberta's oil sand petroleum coke (OSPC) inventory reached 106 million tonnes in 2016, an increase of 8 million tonnes from 2015. Research has been done in recent years to create valuable material from OSPC. In particular, production of activated carbon from OSPC has been studied extensively for various applications. The high carbon nature of OSPC makes it an excellent for precursor for activated carbon. There are mainly two methods for preparing activated carbon from OSPC, chemical and physical activation. Both methods involve mixing OSPC with an activating agent and heating in a furnace for a few hours. Common activating agents used in chemical activation include sodium hydroxide $(\mathrm{NaOH})$, potassium hydroxide $(\mathrm{KOH})$, zinc chloride $\left(\mathrm{ZnCl}_{2}\right)$, phosphoric acid $\left(\mathrm{H}_{3} \mathrm{PO}_{4}\right)$, sulfuric acid $\left(\mathrm{H}_{2} \mathrm{SO}_{4}\right)$ and ferric chloride $\left(\mathrm{FeCl}_{3}\right)$ [2]. Carbon dioxide and steam are used in physical activation.

Activation of carbonaceous materials is well-studied due to the various application of activated carbon. Conventional activation methods are usually energy intensive and time consuming [3]; therefore, microwave assisted chemical activation has attracted interest due to some of its unique advantages including high energy efficiency, rapid heating rate, selective and volumetric heating [4]. This technique is widely applied in biomass activation. Carbonaceous materials are known to have high dielectric loss and can be rapidly heated by microwave [5] The high carbon nature of OSPC makes it an excellent candidate for microwave activation but not much research has been done in this area. This paper aims to review current practices in microwave assisted activation of biomass and OSPC, and while doing so, drawing attention to potential research gaps in using microwave for the preparation of activated carbon from OSPC.

\section{Overview of Microwave Assisted Chemical Activation of Biomass}

The sample preparation steps for microwave activation does not differ much from the conventional method. Procedures usually include size reduction of raw material via crushing or grinding, selection of desired particle size through sieving, oven drying and introduction of activating agent $[3,6,7]$. The activating agents can be either introduced by impregnation or dry mixing. The mixture of biomass and activating agent is sometimes carbonized prior to microwave heating to enhance microwave absorbance [7]. Activation is then carried out inside a microwave oven under inert conditions created by a supply of nitrogen gas. Type of biomass, particle size, activating agent to biomass ratio, microwave power output and heating time are all major factors influencing the development of porous structure of the produced activated carbon. For instance, [3] concluded that tomato leaves are not suitable to be used as starting material for activated carbon due to its high ash content. Activated carbon derived from pine wood showed increasing adsorption capacity 
for allura red and sunset yellow dyes as microwave power output increased from $200 \mathrm{~W}$ to $800 \mathrm{~W}$; however, adsorption capacity decreased for activated carbon produced at 1000W [6]. This is likely due collapse of pores as a result of over-heating. Table 1 presents a summary of activated carbon produced using different biomasses and at different conditions. Specific

Table 1: Comparison of active carbon produced from different biomasses under various conditions.

\begin{tabular}{|c|c|c|c|c|c|c|}
\hline Biomass Type & Activatig Agent & $\begin{array}{c}\text { Biomas To } \\
\text { Activating Agent } \\
\text { Ratio }\end{array}$ & $\begin{array}{l}\text { Microwave } \\
\text { Power (W) }\end{array}$ & $\begin{array}{c}\text { Activation Time } \\
\text { (Min) }\end{array}$ & BET SSA (M2/G) & Reference \\
\hline Pistachio & $\mathrm{KOH}$ & $1: 1.75$ & 600 & 7 & 701 & $\begin{array}{c}\text { Foo \& Hameed } \\
{[12]}\end{array}$ \\
\hline Peanut shell & \multirow{2}{*}{$\mathrm{ZnCl}_{2}$} & \multirow{2}{*}{$1: 4$} & \multirow{2}{*}{600} & \multirow{2}{*}{20} & 1552 & \multirow{2}{*}{ He, et al. [13] } \\
\hline Rice husk & & & & & 1527 & \\
\hline Orange peel & $\mathrm{K}_{2} \mathrm{CO}_{3}$ & $1: 1.25$ & 600 & 6 & 1104 & $\begin{array}{c}\text { Foo \& Hameed } \\
{[12]}\end{array}$ \\
\hline Waste tea & \multirow{4}{*}{$\mathrm{H}_{3} \mathrm{PO}_{4}$} & \multirow{4}{*}{$1: 2$} & \multirow{4}{*}{900} & 3 & 702 & \multirow{4}{*}{ Yagmur [3] } \\
\hline Almond shell & & & & 2 & 1003 & \\
\hline Tomato stem & & & & 3 & 813 & \\
\hline Tomato leave & & & & 2 & 117 & \\
\hline Pine wood & \multirow[b]{2}{*}{$0.01 \mathrm{M} \mathrm{H}_{2} \mathrm{SO}_{4}$} & \multirow[b]{2}{*}{ NA } & 800 & 8 & 221 & \multirow{2}{*}{$\begin{array}{c}\text { Issa, Al-Degs, } \\
\text { Mashal, \& Al } \\
\text { Bakain [6] }\end{array}$} \\
\hline $\begin{array}{l}\text { Arabica coffee } \\
\text { residue }\end{array}$ & & & 600 & 8 & 165 & \\
\hline
\end{tabular}

\section{Application of Microwave Heating in OSPC Activation}

Porous carbon produced from OSPC using the conventional activation method has been applied in various areas such as environmental treatment, impurities removal and electrical energy storage [8,2,9]. Highly activated OSPC is achieved with SSA values in the range of $800-2000 \mathrm{~m}^{2} / \mathrm{g}$ using OSPC to activating agent ratio of $1: 1.5$ to $1: 2.5$ (activation temperature $850-900 \mathrm{C}$; duration 2 hours) $[8,9]$. With the aid of rapid microwave heating, the production of activated carbon from OSPC could become more energy and cost efficient. Chen and [5] demonstrated the feasibility of fast preparation of activated carbon using microwave radiation. Two types of OSPC, fluid coke and delayed coke (particle size: $0.3-0.42 \mathrm{~mm}$ ) were activated using a OSPC to $\mathrm{KOH}$ ratio of $1: 1$ for 10 minutes [10]. The resultant activated carbon was found to be mostly microporous with SSA values of $1131 \mathrm{~m}^{2} / \mathrm{g}$ and $440 \mathrm{~m}^{2} / \mathrm{g}$ for delayed and fluid coke respectively. In an evaluation of the effect of various activation conditions, iodine number was used as an indicator of porous development. After comparing key activation parameters such as particle size, OSPC to $\mathrm{KOH}$ ratio and microwave heating time, it was concluded: smaller particle sizes resulted in higher activation level; a higher ratio of $\mathrm{KOH}$ was observed to produce activated carbon with higher iodine number but the increase in porosity was not proportional to the increase in $\mathrm{KOH}$; microwave activation of 10 minutes was sufficient to produce activated carbon from delayed coke with comparable iodine number with commercial activation carbon [10]. surface area (SSA) is used as a measure for comparing porous development among them. It can be seen that activated carbon with high SSA can be produced using cheap biomasses in a short period of time, yet the use of microwave assisted activation for OSPC is not well-studied.
In a current study, the effect of dry mixing vs. wet impregnation and OSPC to $\mathrm{KOH}$ ratio on microwave activation of fluid coke was investigated [11]. Dry mixing was carried out by mixing ground $\mathrm{KOH}$ pellets with fluid coke in the size range of $105-150 \mathrm{~mm}$, while wet mixing was done by impregnating OSPC in $\mathrm{KOH}$ solution at room temperature for 12 hours. The activation was carried out at a microwave output power of $800 \mathrm{~W}$ for 10 minutes. The extent of activation was not observed to be different in terms of iodine number. When the $\mathrm{KOH}$ dosage was reduced by half (from 1:1 to 1:0.5), iodine number decreased drastically (from $1009 \mathrm{mg} / \mathrm{g}$ to $196 \mathrm{mg} / \mathrm{g}$ ). This could be a result of insufficient reagent as well as microwave absorption. The amount of $\mathrm{KOH}$ introduced to the system was observed to have an effect on reaction temperature as $\mathrm{KOH}$ was reported to absorb microwave strongly [4]. Lower reaction temperature was observed for samples activated with lower $\mathrm{KOH}$ weight percent. This conclusion is inconsistent with Chen \& Hashisho's findings that more power was needed to heat and activate samples with high $\mathrm{KOH}$ weight percent [12-14].

A deficiency of research exists in the field of microwave assisted chemical activation of OSPC. Additional work is required to further investigate the effect of activating agent on reaction temperature as well as to explore different activating agents and the optimal ratio between OSPC.

\section{Conclusion}

Microwave assisted chemical activation has been demonstrated to produce highly porous carbon. This method is well-researched in the field of biomass activation, but not 


\section{Recent Advances in Petrochemical Science}

enough work has been done for OSPC activation. Since OSPC is readily available at a cheap price and the activated product has many applications in different areas, there exist a great potential for microwave activation of OSPC. Microwave assisted activation allows for higher energy efficiency and lower chemical cost compared to conventional chemical activation. Although current work has proven the feasibility of fast activation of OSPC using microwave radiation, optimization of activation conditions needs to be further studied for the wide application of this technique.

\section{References}

1. Alberta Energy Regulator (2018) Crude bitumen production. Retrieved from Alberta Energy Regulator.

2. Sarkar B (2013) Adsorption of single-ring model naphthenic acid from oil sands tailings pond water using petroleum coke-derived activated carbon, Adsorption of single-ring model naphthenic acid from oil sands. University of Toronto, Canada.

3. Yagmur E (2012) Preparation of low cost activated carbons from various biomasses with microwave energy. Journal of Porous Matter 19(6): 995-1002.

4. Namazi AB (2014) Microwave-assisted production of activated carbon from pulp mill sludge with white liquor. Univeristy of Toronto, Canada.

5. Chen H, Hashisho Z (2012) Effects of microwave activation conditions on the properties of activated oil sands coke. Fuel Processing Technology 102: 102-109.

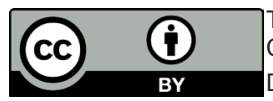

This work is licensed under Creative Commons Attribution 4.0 License

DOI: 10.19080/RAPSCI.2018.05.555656
6. Issa AA, Al-Degs YS, Mashal K, Bakain ARZ (2014) Fast activation of natural biomasses by microwave heating. Journal of Industrial and Engineering Chemistry 21: 230-238.

7. Foo K, Hameed B (2011) Preparation and characterization of activated carbon from pistachio nut shells via microwave-induced chemical activation. Biomass and Bioenergy 35(7): 3257-3261.

8. Shi L (2017) Fate of sulfur during production of oil sands petroleum coke derived-activated carbon. Fate of sulfur during production of oil sands petroleum coke. Univeristy of Toronto, Canada.

9. Zuliani JE, Kirk DW, Jia CQ Tong S (2014) Activated oil sands fluid coke for electrical double-layer capacitors. Journal of Power Sources 271: 326-333.

10. Chen H, Hashisho Z (2012) Fast preparation of activated carbon from oil sands coke using microwave-assisted activation. Fuel 95: 178-182.

11. Bai S (2018) Microwave assisted chemical activation of fluid coke. MEng research report, Univeristy of Toronto, Canada.

12. Foo K, Hameed B (2012) Preparation, characterization and evaluation of adsorptive properties of orange peel based activated carbon via microwave induced $\mathrm{K}_{2} \mathrm{CO}_{3}$ activation. Bioresource Technology 104 679-686.

13. He X, Ling P, Qiu J, Yu M, Zhang X, et al. (2013) Efficient preparation of biomass-based mesoporous carbons for super capacitors with both high energy density and high power density. Journal of Power Sources 240: 109-113.

14. Stockman L (2013) Petroleum Coke: the coal hiding in the Tar Sands Oil Change International, Washington DC, USA.

\section{Your next submission with Juniper Publishers will reach you the below assets}

- Quality Editorial service

- Swift Peer Review

- Reprints availability

- E-prints Service

- Manuscript Podcast for convenient understanding

- Global attainment for your research

- Manuscript accessibility in different formats ( Pdf, E-pub, Full Text, Audio)

- Unceasing customer service

Track the below URL for one-step submission https://juniperpublishers.com/online-submission.php 